\title{
Cupping Therapy Simulation Course; A Pilot Study Assessing Self Reporting of Confidence, Expectations/Satisfaction and Performance
}

\author{
Tamer Aboushanab $^{1 *}$, Mohammed Khalil ${ }^{1}$, Ahmed El-Olemy ${ }^{1,2}$, Saud Alsanad $^{1,3}$ \\ ${ }^{1}$ National Center for Complementary and Alternative Medicine, Ministry of Health, Riyadh, Saudi Arabia \\ ${ }^{2}$ Department of Public Health and Community Medicine, Faculty of Medicine, Tanta University, Egypt. \\ ${ }^{3}$ College of Medicine, Al-Imam Mohammad Ibn Saud Islamic University (IMSIU)
}

Al-Nada, Riyadh 13317-4233, Saudi Arabia.

\begin{abstract}
This paper aimed to assess self-reporting of confidence, expectations/satisfaction, and performance of medical students before and after the cupping therapy simulation training course and to validate cupping simulation training evaluation questionnaire (CSTEQ). It was a pilot study to evaluate cupping therapy simulation course provided by National Center for Complementary and Alternative Medicine (NCCAM). The number of participants was 29/41 (70.7\%) (20 females and 9 males) before training and 20/41 (48.9\%) ( 9 females and 11 males) after training who returned the (CSTEQ) questionnaire. A significant improvement of performance scale and total score were noted after the cupping simulation training. Significant differences in confidence $(\mathrm{P}=0.013)$, expectations/satisfaction $(\mathrm{P}=0.001)$, performance $(\mathrm{P}=0.007)$ and total scoring $(\mathrm{P}=0.001)$ between male and female medical students were noted in favor of males. We can conclude that medical students reported significant improvement in performance and overall scoring after cupping therapy simulation course. Cupping simulation training evaluation questionnaire (CSTEQ) may be a reliable test tool. Cupping therapy simulation course should be encouraged, updated and extended to satisfy the learning needs especially of the female medical student. Future large-scale studies were recommended.
\end{abstract}

Keywords: Simulation, cupping therapy, hijama, training, medical students

\section{Introduction}

Simulation-based medical training is the modern-day tool for medical teaching [1]. It includes performing a medical procedure on simulators to increase the confidence and skills of trainees before conducting the procedures on humans [2]. Cupping therapy is a widely used traditional healing method [3]. It was practiced for more than 5000 years [4]. Most of the civilizations practiced cupping therapy such as ancient Egyptians, Chinese, Greek, Romans, and Arabs [5]. Cupping practice involved applying cups on selected body points by sucking air to induce sub-atmospheric pressure inside the cup either by heat or suction [6]. There are many types of cupping therapy. Dry, wet, flash, massage, needle, moxa, water and sports cupping are popular cupping types [7]. 
Artificial skin simulator is previously used to train medical students how to perform surgical skin sutures [8]. The Saudi National Center for Complementary and Alternative Medicine (NCCAM) developed and introduced this innovative idea to use artificial skin simulator in cupping therapy training as a simulation method [8]. Artificial skin used was $180 * 100 * 25 \mathrm{~mm}$ in size. It was made from durable, non-toxic silicon to simulate the layers of the skin and subcutaneous fat and muscles.

The cupping therapy simulation course was two days orientation training for medical students as a part of complementary medicine and integrative health elective course. The aim of this pilot study was to assess self-reporting of confidence, expectations/satisfaction, and performance before and after the cupping therapy simulation course as a guide for future large studies and simulation cupping training programs and to validate cupping simulation training evaluation questionnaire (CSTEQ).

\section{Materials and Methods}

\subsection{Study Design}

The study was a pilot study to evaluate the cupping simulation training course. This study was a pre- and post-training, self-reported survey. Medical students were asked to complete the questionnaire before and immediately after the training course using a questionnaire developed by the NACCM. The evaluation focused on confidence, expectations/satisfaction, and performance. The training course was provided for males and females separately.

\subsection{Target Population}

Fourth-year medical students, from Dar Al Uloom University, KSA, 16 males, and 25 females attending cupping simulation training course as a part of complementary medicine and integrative health elective course provided by National Center for Complementary and Alternative Medicine (NCCAM) were the target population of the study.

\subsection{Participants}

The number of participants was 29/41 (70.7\%) (20 females and nine males) before and 20/41 (48.9\%) (9 females and 11 males) after training who returned the questionnaire.

\subsection{The Questionnaire}

Cupping simulation training evaluation questionnaire (CSTEQ) was developed, predefined by an internal committee of NCCAM, Riyadh, Saudi Arabia. It was not evaluated before. One of the aims of this study to evaluate the questionnaire. The questionnaire (Table 1) had fifteen items. It was divided into three scales; which were confidence, expectations/satisfaction, and performance. Each scale included five questions using five-Likert scale response. Participants were asked to fill in the questionnaire before and after the training on a five-point scale from 1 to 5 which included: strongly agree, agree, neutral, disagree or strongly disagree. Ethical considerations were ensured through approval of the ethical committee of NCCAM in Riyadh. Participation was voluntary. The consent from respondent has been taken by informing them the purpose of this survey.

\subsection{Statistical Analysis}

Statistical Package for Social Sciences (SPSS) Software Version 20 was used for data entry, coding, data management and analysis. The results were described as frequencies and percentages for all research variables. We used non-parametric tests due to their fewer assumptions of normal distributions of responses. Wilcoxon Signed Ranks Test was used to compare repeated responses. Independent samples Mann Whitney $\mathrm{U}$ test was used to compare gender difference. $\mathrm{P}<0.05$ was considered significant. Internal reliability of the questionnaire and scales was evaluated by Cronbach's alpha test 
Aboushanab et al. Adv. J Social Sci.; Vol. 1 Issue 1, pp: 53-59, November 2017

Table 1: Questionnaire items and results before and after the trial

\begin{tabular}{|c|c|c|c|}
\hline \multirow{4}{*}{ I feel confident in doing cupping therapy (C) } & & before & after \\
\hline & Disagree/Strongly disagree & $20.7 \%$ & $15.0 \%$ \\
\hline & Neutral & $27.6 \%$ & $20.0 \%$ \\
\hline & Agree/Strongly disagree & $51.7 \%$ & $65.0 \%$ \\
\hline \multirow{3}{*}{$\begin{array}{l}\text { Doing Cupping therapy on artificial skin can make } \\
\text { me more confident in performing cupping more } \\
\text { than doing cupping on real human volunteers }(\mathrm{C})\end{array}$} & Disagree/Strongly disagree & $3.4 \%$ & $10.0 \%$ \\
\hline & Neutral & $27.6 \%$ & $35.0 \%$ \\
\hline & Agree/Strongly agree & $69.0 \%$ & $55.0 \%$ \\
\hline \multirow{3}{*}{$\begin{array}{l}\text { I feel confident in giving medical advice and } \\
\text { consultation regarding cupping therapy use (C) }\end{array}$} & Disagree/Strongly disagree & $17.2 \%$ & $5.0 \%$ \\
\hline & Neutral & $31.0 \%$ & $25.0 \%$ \\
\hline & Agree/Strongly agree & $51.7 \%$ & $70.0 \%$ \\
\hline \multirow{3}{*}{$\begin{array}{l}\text { I feel confident in handling cupping therapy } \\
\text { instruments }(C)\end{array}$} & Disagree/Strongly disagree & $10.3 \%$ & $20.0 \%$ \\
\hline & Neutral & $48.3 \%$ & $25.0 \%$ \\
\hline & Agree/Strongly agree & $41.4 \%$ & $55.0 \%$ \\
\hline \multirow{3}{*}{$\begin{array}{l}\text { I feel confident in explaining cupping therapy } \\
\text { concepts to colleagues (C) }\end{array}$} & Disagree/Strongly disagree & $6.9 \%$ & $10.0 \%$ \\
\hline & Neutral & $51.7 \%$ & $15.0 \%$ \\
\hline & Agree/Strongly agree & $41.4 \%$ & $75.0 \%$ \\
\hline \multirow{3}{*}{$\begin{array}{l}\text { Using artificial skin for cupping training will help } \\
\text { in improving my skills (E/S) }\end{array}$} & Disagree/Strongly disagree & $6.9 \%$ & $15.0 \%$ \\
\hline & Neutral & $31.0 \%$ & $20.0 \%$ \\
\hline & Agree/Strongly agree & $62.1 \%$ & $65.0 \%$ \\
\hline \multirow{3}{*}{$\begin{array}{l}\text { Training on human volunteers is more effective } \\
\text { method of training than cupping artificial skin } \\
\text { model (E/S) }\end{array}$} & Disagree/Strongly disagree & $13.8 \%$ & $5.0 \%$ \\
\hline & Neutral & $17.2 \%$ & $10.0 \%$ \\
\hline & Agree/Strongly agree & $69.0 \%$ & $85.0 \%$ \\
\hline \multirow{3}{*}{$\begin{array}{l}\text { Training on cupping artificial skin model is more } \\
\text { safe method of training than training on real human } \\
\text { (E/S) }\end{array}$} & Disagree/Strongly disagree & $10.3 \%$ & $10.0 \%$ \\
\hline & Neutral & $20.7 \%$ & $20.0 \%$ \\
\hline & Agree/Strongly agree & $69.0 \%$ & $70.0 \%$ \\
\hline \multirow{3}{*}{$\begin{array}{l}\text { Participating in simulation scenarios will help me } \\
\text { in my decision-making skills (E/S) }\end{array}$} & Disagree/Strongly disagree & $10.3 \%$ & $5.0 \%$ \\
\hline & Neutral & $27.6 \%$ & $25.0 \%$ \\
\hline & Agree/Strongly agree & $62.1 \%$ & $70.0 \%$ \\
\hline \multirow{3}{*}{$\begin{array}{l}\text { The cupping training will add to my medical } \\
\text { knowledge }(\mathrm{E} / \mathrm{S})\end{array}$} & Disagree/Strongly disagree & $10.3 \%$ & $5.0 \%$ \\
\hline & Neutral & $20.7 \%$ & $15.0 \%$ \\
\hline & Agree/Strongly agree & $69.0 \%$ & $80.0 \%$ \\
\hline \multirow{3}{*}{$\begin{array}{l}\text { I am able to use cupping therapy lancing tools } \\
\text { (surgical blades and auto lancet) }(\mathrm{P})\end{array}$} & Disagree/Strongly disagree & $24.1 \%$ & $5.0 \%$ \\
\hline & Neutral & $51.7 \%$ & $20.0 \%$ \\
\hline & Agree/Strongly agree & $24.1 \%$ & $75.0 \%$ \\
\hline \multirow[t]{3}{*}{ I am able to use cupping therapy instruments $(\mathrm{P})$} & Disagree/Strongly disagree & $41.4 \%$ & $5.0 \%$ \\
\hline & Neutral & $31.0 \%$ & $20.0 \%$ \\
\hline & Agree/Strongly agree & $27.6 \%$ & $75.0 \%$ \\
\hline \multirow{3}{*}{$\begin{array}{l}\text { I am able to use auto lancet device effectively than } \\
\text { surgical blade }(\mathrm{P})\end{array}$} & Disagree/Strongly disagree & $27.6 \%$ & $5.0 \%$ \\
\hline & Neutral & $48.3 \%$ & $30.0 \%$ \\
\hline & Agree/Strongly agree & $24.1 \%$ & $65.0 \%$ \\
\hline \multirow{3}{*}{$\begin{array}{l}\text { I am able to provide consultation to patients } \\
\text { seeking advice regarding cupping therapy }(\mathrm{P})\end{array}$} & Disagree/Strongly disagree & $20.7 \%$ & $10.0 \%$ \\
\hline & Neutral & $51.7 \%$ & $30.0 \%$ \\
\hline & Agree/Strongly agree & $27.6 \%$ & $60.0 \%$ \\
\hline \multirow{3}{*}{$\begin{array}{l}\text { I am able to create a cupping therapy treatment } \\
\text { plan }(\mathrm{P})\end{array}$} & Disagree/Strongly disagree & $41.4 \%$ & $5.0 \%$ \\
\hline & Neutral & $27.6 \%$ & $10.0 \%$ \\
\hline & Agree/Strongly agree & $31.0 \%$ & $85.0 \%$ \\
\hline
\end{tabular}

$\mathrm{C}=$ Confidence, $\mathrm{E} / \mathrm{S}=$ Expectations/Satisfaction \& $\mathrm{P}=$ Performance

\section{Results}

Cronbach's alpha of confidence scale was 0.81 , expectations/satisfaction scale was 0.85 , performance scale was 0.94 , and total evaluation was 0.91 . These values showed good internal consistency of the scales. A significant improvement of total scoring after simulation training was reported $(\mathrm{P}=0.013)$. Performance scale showed significant improvement after the trial $(\mathrm{P}=0.000)$ while confidence $(\mathrm{P}=0.18)$ and expectations/ satisfaction $(\mathrm{P}=0.341)$ scales were not significant after simulation training as given in Table 2 and represented in Figure 1. 
Cupping Therapy Simulation Course; A Pilot Study Assessing Self Reporting of Confidence, Expectations/Satisfaction and Performance

Table 2: Comparison between confidence, expectations, and performance items before and after training.

\begin{tabular}{|l|r|r|r|r|}
\hline & Total Score & Confidence & $\begin{array}{c}\text { Expectations } \\
\text { /satisfaction }\end{array}$ & Performance \\
\hline Asymp. Sig. (2-tailed) & .029 & .206 & .319 & .002 \\
\hline Wilcoxon Signed Ranks Test
\end{tabular}

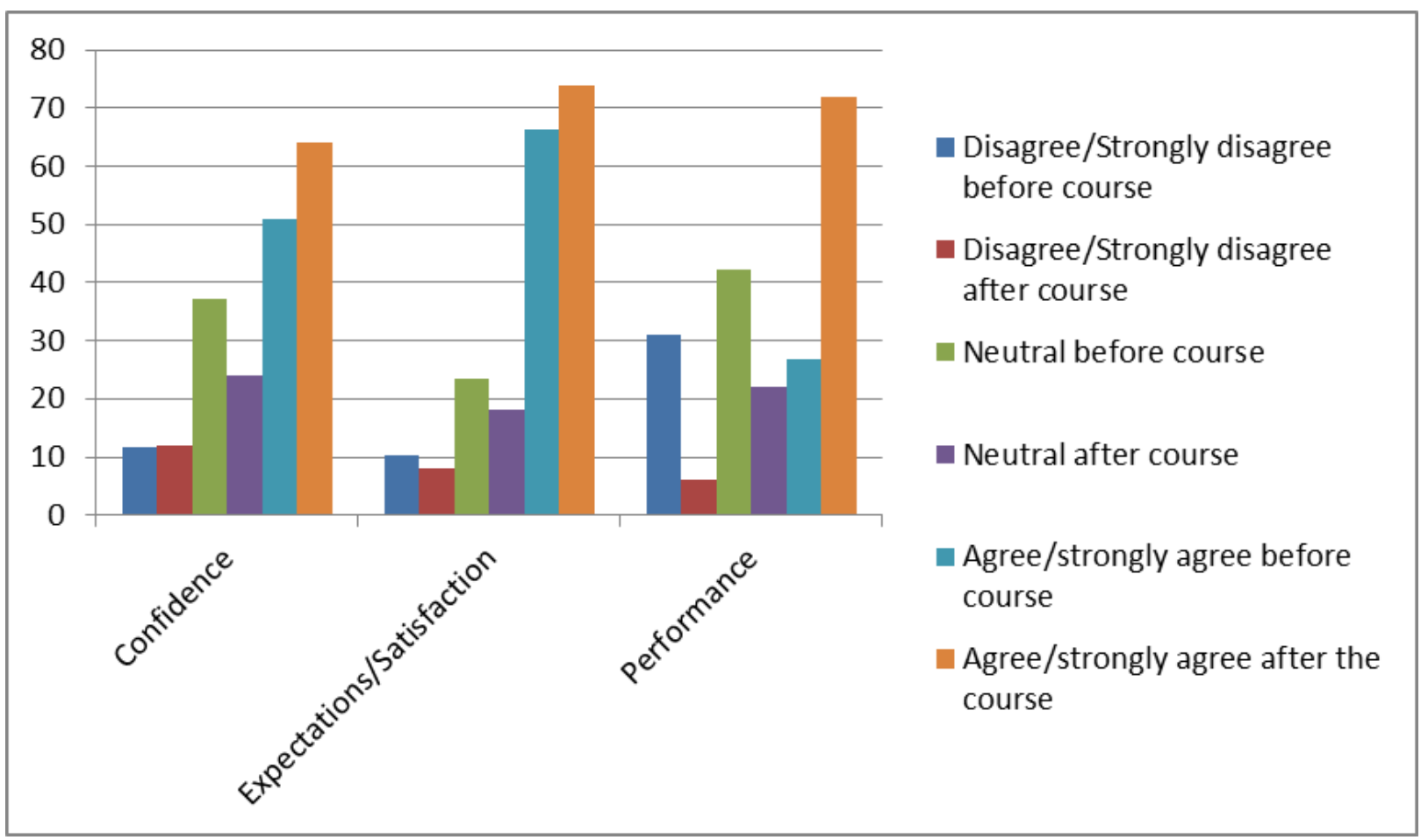

Figure 1: A summary of study results

The most "strongly agreed" item before the trial was: "Training on cupping artificial skin model is a more safe method of training than training on a real human." and "Training on human volunteers is a more effective method of training than cupping artificial skin model . 34.5\% each. Furthermore, the most "strongly agreed" item after training was: "I feel confident in explaining cupping therapy concepts to colleagues", and "The cupping training will add to my medical knowledge", 45\% each. The item " I am able to create a cupping therapy treatment plan" was the most "strongly disagreed" item before training, $13.8 \%$ while " I feel confident in doing cupping therapy " was the most "strongly disagreed" item after the training, $10 \%$. Interestingly, the results showed significant differences in confidence $(\mathrm{P}=0.013)$, expectations/satisfaction $(\mathrm{P}=0.001)$, performance $(\mathrm{P}=0.007)$ and total scoring $(\mathrm{P}=0.001)$ between males and female medical students in favor of male participants (Table 3).

Table 3: Comparison between confidence, expectations, and performance items by gender

\begin{tabular}{|c|l|c|}
\hline & \multicolumn{1}{|c|}{ Null Hypothesis } & Sig \\
\hline 1 & The distribution of confidence scale is the same between categories of Gender & 0.013 \\
\hline 2 & $\begin{array}{l}\text { The distribution of expectation/satisfaction scale is the same between categories } \\
\text { of Gender }\end{array}$ & 0.001 \\
\hline 3 & \begin{tabular}{l} 
The distribution of performance scale is the same between categories of Gender \\
\hline 4
\end{tabular} & The distribution of total scoring is the same between categories of Gender \\
\hline \multicolumn{2}{|l|}{ Mann Whitney U test } & 0.007 \\
\hline
\end{tabular}




\section{Discussion}

In this study, a significant improvement of total scoring after simulation training indicating overall benefits of cupping therapy simulation course. This result is in accordance with Ten Eyck et al. [10], who reported more satisfaction of medical students with the simulation-based training compared with group discussion. Numerous studies reported significant improvement in clinical skills and performance after medical simulation training [11, 12]. The present study also reported a significance improvement of performance scale which is an indicator of increasing self-confidence in clinical performance. However, evaluation of clinical skills is recommended in future studies before and after simulation training.

The most "strongly agreed" item before the training was: "Training on cupping artificial skin model is a safer method of training than training on real human ", and "Training on human volunteers is more effective method of training than cupping artificial skin model ". These two items were not opposite, but they complement each other. While training on a human was more effective, training on artificial skin or any simulator was safer. It represented a preliminary stage in cupping training to acquire basic cupping skills without fear of making errors before beginning training on real human patients. The most "strongly agreed" items after training was: "I feel confident in explaining cupping therapy concepts to colleagues", and "The cupping training will add to my medical knowledge" which reflected the success of achieving the main goal of this short training course ( 2 days course). The course was an orientation course. The main goal was to increase awareness and knowledge regarding cupping therapy practice.

Our study reported that the item "I am able to create a cupping therapy treatment plan" was the most "strongly disagreed" item before training. The results was logical due to the little knowledge about planning cupping session before training course while no one reported "strongly disagree" for this item after the training which reflected the increase of knowledge. The present study found the item "I feel confident in doing cupping therapy" was the most "strongly disagreed" item after the training. The training was an orientation course, so the main goal was not to prepare students to practice cupping therapy. Also, introducing wet cupping therapy (the most common type in Arabic countries) as a surgical procedure with practical professional rules, special skills, safety protocols, and precautions was a new knowledge for participants. Lastly, the duration of the course was too short to do the extended practice of cupping therapy procedure. Improvements of confidence and expectations/satisfaction scales were noted but not significant. On the other hand, improvement of performance scale and the total score was significant. This may be an indicator that the course was relatively satisfied medical student's expectations and needs.

Previously, differences between male and female students were reported in solving practical tasks and visuospatial learning in favor of male [13,14]. Evidently, gender differences were also reported in performance on simulation trainers [15]. Our results showed gender differences in reporting confidence, expectations/satisfaction, and performance in favor of males. These results may be due to underestimation of clinical performance and lack of interest in surgical procedures by females which did not reflect actual differences in performance as reported previously $[16,17]$. Extended hours of repeated clinical practice were recommended to increase confidence and performance of male and female medical students [18]. The high satisfaction and self-reported performance by male medical students may not reflect their actual performance in theoretical exams rather than females who reported effectively their actual performance previously as studied by Schlickum et al. [19].

\section{Conclusion}

Male and female medical students may be different in reporting confidence and performance before and after cupping therapy simulation course. Cupping Simulation Training Evaluation Questionnaire (CSTEQ) may be a reliable test tool. Cupping therapy simulation course should be encouraged, updated and extended to satisfy the learning needs especially of female medical students. Large-scale studies are recommended to explore more cupping simulation aspects and confirm results. Development of standard cupping simulation training questionnaires and skills evaluation forms and tools is required for future cupping therapy research. 


\section{Declarations}

\subsection{Study Limitations}

This study had several limitations. The low response rate in the post training questionnaire was an important limitation. However, this was a pilot study, and we can use these results as a guide to design future large studies. The absence of actual performance evaluation was another important limitation. We encourage future large studies to evaluate the actual performance skills objectively and compare the results with self-reporting of performance. The lack of previous studies in the field of cupping therapy simulation training was also a limitation. Importantly, the lack of standard questionnaires, and cupping therapy performance skills evaluation forms were major limitations. However, this was a relatively new field of training and we are expecting more studies in the future to improve the quality of the study and the reliability of the questionnaire.

\subsection{Ethical Approval}

Ethical approval has been taken by the IRB: National Center for Complementary and Alternative Medicine, Riyadh with approval number NCCAM-2016-6.

\subsection{Informed Consent}

The consent from the participants has been taken by informing them the purpose of this survey

\subsection{Funding Source}

None

\subsection{Competing Interests}

Author declared, no conflict of interest to disclose.

\section{How to Cite this Article:}

Aboushanab, T., Khalil, M., El-Olemy, A., \& Alsanad, S. (2017, November 30). Cupping Therapy Simulation Course; A Pilot Study Assessing Self Reporting of Confidence, Expectations/Satisfaction and Performance. Advanced Journal of Social Science, 1(1), 53-59. https://doi.org/https://doi.org/10.21467/ajss.1.1.53-59

\section{References}

[1] William C. McGaghie, Saul B. Issenberg, Jeffrey H. Barsuk, and Diane B. Wayne. "A critical review of simulation-based mastery learning with translational outcomes." Medical Education 48, no. 4 (2014): 375-385.

[2] Kevin Kunkler. "The role of medical simulation: an overview." The International Journal of Medical Robotics and Computer Assisted Surgery 2, no. 3 (2006): 203-210.

[3] Huijuan Cao, Mei Han, Xun Li, Shangjuan Dong, Yongmei Shang, Qian Wang, Shu Xu, and Jianping Liu. "Clinical research evidence of cupping therapy in China: a systematic literature review." BMC complementary and alternative medicine 10, no. 1 (2010): 70.

[4] Asif Ahmed, Rafeeq Alam Khan, Amjad Ahsan Ali, and M. Ahmed Mesaik. "Effect of wet cupping therapy on virulent cellulitis secondary to honey bee sting-a case report." Journal of Basic \& Applied Sciences 7, no. 2 (2011).

[5] Naseem Akhtar Qureshi, Gazzaffi Ibrahim Ali, Tamer Shaban Abushanab, Ahmed Tawfik El-Olemy, Meshari Saleh Alqaed, Ibrahim S. El-Subai, and Abdullah MN Al-Bedah. "History of cupping (Hijama): a narrative review of literature." Journal of Integrative Medicine 15, no. 3 (2017): 172-181.

[6] Müzeyyen Arslan, Nurcan Gökgöz, and Şenol Dane. "The effect of traditional wet cupping on shoulder pain and neck pain: A pilot study." Complementary therapies in clinical practice 23 (2016): 30-33.

[7] Abdullah Mohammed Al-Bedah, Tamer Shaban Aboushanab, Meshari Saleh Alqaed, Naseem Akhtar Qureshi, Imen Suhaibani, Gazzaffi Ibrahim, and Mohammed Khalil. "Classification of Cupping Therapy: A tool for modernization and standardization." Journal of Complementary and Alternative Medical Research 1, no. 1 (2016): 1-10.

[8] Roger Kneebone. "Simulation in surgical training: educational issues and practical implications." Medical education 37, no. 3 (2003): 267-277.

[9] Abdullah M.Al-Bedah, Tamer S. Aboushanab, Meshari S. Alqaed, Naseem Akhtar Qureshi, Jamal A. Basahi, Ahmed T. El-Olemy, and Mohamed Khalil. "The use of medical simulation in cupping therapy training: a novel idea from the national center for complementary and alternative medicine." J Complement Altern Med Res 1, no. 3 (2016): 1-4.

[10] Raymond P Ten Eyck, Matthew Tews, and John M. Ballester. "Improved medical student satisfaction and test performance with a simulation-based emergency medicine curriculum: a randomized controlled trial." Annals of emergency medicine 54, no. 5 (2009): 684-691. 
Aboushanab et al. Adv. J Social Sci.; Vol. 1 Issue 1, pp: 53-59, November 2017

[11] Randolph H. Steadman, Wendy C. Coates, Yue Ming Huang, Rima Matevosian, Baxter R. Larmon, Lynne McCullough, and Danit Ariel. "Simulation-based training is superior to problem-based learning for the acquisition of critical assessment and management skills." Critical care medicine 34, no. 1 (2006): 151-157.

[12] Leigh V. Evans, Kelly L. Dodge, Tanya D. Shah, Lewis J. Kaplan, Mark D. Siegel, Christopher L. Moore, Cara J. Hamann, Zhenqiu Lin, and Gail D'onofrio. "Simulation training in central venous catheter insertion: improved performance in clinical practice." Academic Medicine 85, no. 9 (2010): 1462-1469.

[13] Jos J. Adam, "Gender differences in choice reaction time: evidence for differential strategies." Ergonomics 42, no. 2 (1999): 327-335.

[14] Jennifer T. Sneider, Derek A. Hamilton, Julia E. Cohen-Gilbert, David J. Crowley, Isabelle M. Rosso, and Marisa M. Silveri. "Sex differences in spatial navigation and perception in human adolescents and emerging adults." Behavioural processes 111 (2015): 4250.

[15] Chad M. Thorson, Jason P. Kelly, R. Armour Forse, and Kiran K. Turaga. "Can we continue to ignore gender differences in performance on simulation trainers?" Journal of Laparoendoscopic \& Advanced Surgical Techniques 21, no. 4 (2011): 329-333.

[16] Rebecca L. Flyckt, Eliza E. White, Linnea R. Goodman, Catherine Mohr, Sanjeev Dutta, and Kristine M. Zanotti. "The Use of Laparoscopy Simulation to Explore Gender Differences in Resident Surgical Confidence." Obstetrics and gynecology international 2017 (2017).

[17] Kyoko Nomura, Eiji Yano, and Tsuguya Fukui. "Gender differences in clinical confidence: a nationwide survey of resident physicians in Japan." Academic Medicine 85, no. 4 (2010): 647-653.

[18] Tyrone Donnon, Jean-Gaston DesCôteaux, and Claudio Violato. "Impact of cognitive imaging and sex differences on the development of laparoscopic suturing skills." Canadian journal of surgery 48, no. 5 (2005): 387.

[19] Marcus Schlickum, Li Felländer-Tsai, Leif Hedman, and Lars Henningsohn. "Endourological simulator performance in female but not male medical students predicts written examination results in basic surgery." Scandinavian journal of urology 47, no. 1 (2013): $38-42$.

Publish your research article in AIJR journals-

$\checkmark$ Online Submission and Tracking

$\checkmark$ Peer Reviewed

$\checkmark$ Rapid decision

$\checkmark$ Immediate Publication after acceptance

$\checkmark$ Open Access (Articles freely available online)

$\checkmark$ Retain full copyright of your article.

Submit your article at journals.aijr.in 